\title{
Faith, heresy and the cancer stem cell hypothesis
}

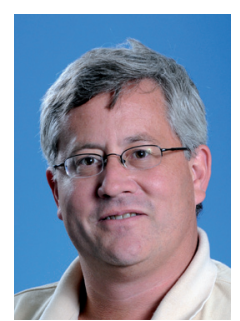

“...one cannot help but wonder: are we truly debating the basic question of the existence of a cancer stem cell? Or are we confusing this question with the myriad of questions related to their nature should they exist?"

\section{Michael T Lewis}

Lester and Sue Smith Breast Center and the Department of Molecular and Cellular Biology, Baylor College of Medicine, One Baylor Plaza, Room N1210, BCM600, Houston TX 77030, USA = Tel: . +1 7137983296 n. Fax: +1 7137981659 nmtlewis@bcm.tmc.edu

Groundbreaking studies by Ken DeOme and others in the 1950s definitively showed that the adult mammary gland contains epithelial stem cells with the ability to regenerate a fully functional ductal tree upon transplantation [1]. These stem cells are defined by their capacity to self-renew (reproduce new stem cells) and to give rise to all differentiated cell types normally present in the gland.

While the existence of normal mammary epithelial stem cells is uncontested, the hypothesis that cancers, including those of the breast, arise from and contain cells possessing properties similar to those of normal tissue stem cells (i.e., 'cancer stem cells' or 'cancer-initiating cells') has caused a remarkable level of debate, as well as a certain level of outright confusion [2-9]. Indeed, the controversy is not limited to breast cancer, but extends to cancers of other organs, with the division between those favoring the cancer stem cell hypothesis, and those not favoring it, likened recently to a religious schism [10].

There are at least four issues that continue to serve as sticking points in the cancer stem cell debate. First, and foremost, is confusion over the use of the term 'stem cell' in the designation for the hypothesis. Use of this term leads to difficulty distinguishing between the question of whether cancer is driven by a cell type displaying behaviors characteristic of stem cells, from the equally important question of whether the normal tissue stem cell, and progenitor cells derived from them, are the cells of origin for cancer [2]. Second is our difficulty separating the question of the existence of such a cell type from the question of their frequency within a given tumor [11,12]. Third, the suggestion has been raised that, if the cancer stem cell hypothesis is correct, its veracity would exclude the possibility of clonal selection for tumor cells acquiring selfrenewal or an additional growth advantage over time (the clonal selection hypothesis), addressed in [13]. Fourth, it has also been suggested that, if the hypothesis is correct and stem cells are intrinsically resistant to current therapies, this should exclude the possibility that acquired treatment resistance can arise within a tumor [5].

Given these difficulties, one cannot help but wonder: are we truly debating the basic question of the existence of a cancer stem cell? Or are we confusing this question with the myriad of questions related to their nature should they exist? One also wonders: are we not, at times, in danger of ascribing cancer stem cells with characteristics that we have not yet demonstrated experimentally? Keeping these questions entirely separate is extremely difficult, and approaching them experimentally is a monumental task. However, it is essential that questions concerning the cell of origin, relative frequency, quiescence, regulation, therapy resistance and metastatic behavior of cancer stem cells be addressed wholly independently of the question of their existence.

Arguments for the existence of tumor-initiating 'cancer stem cells' are rooted ultimately in cell theory. A central tenet of cell theory states that, other than the first cell, all cells arise from pre-existing cells. Since all cancers are composed of cells, and have, in most cases, been demonstrated to be clonally derived, most cancers must arise from a single, pre-existing cell - a 'tumorinitiating cell'. The cancer stem cell hypothesis proposes that tumor-initiating 'cancer stem cells' arise from cells that either innately possess or acquire the ability to self-renew (reproduce a new tumor-initiating cell) and serve as a precursor cell able to generate all other cell types characteristic of a given tumor $[2,8]$. Thus, the term 'stem cell' in the 'cancer stem cell hypothesis' refers to a defining set of cellular behaviors responsible for tumor formation, and not necessarily to the identity of the cell of origin.

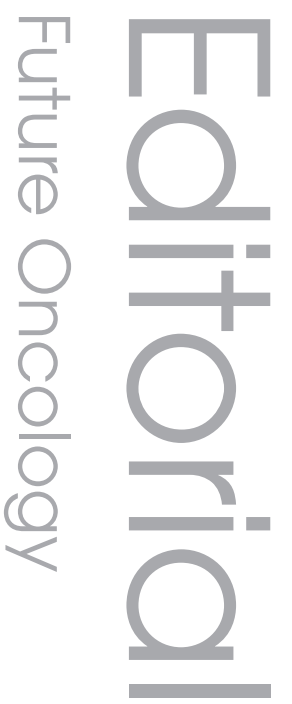

future medicine $^{\text {posg }} \mathbf{f s}$ 
With respect to breast cancer, the existence of tumorigenic cells cannot be denied. However, if one accepts this functional definition of a cancer stem cell, it is difficult to dismiss the mounting evidence in both human and mouse in vivo models that cells displaying the defining functions of cancer stem cells do, in fact, exist, and that tumor cell populations enriched for such cells can be isolated prospectively using either cell surface markers $\left(\mathrm{CD} 44^{+}\right.$; $\mathrm{CD} 24^{\text {low/ }}$ in at least some human breast cancers [14] and $\mathrm{CD} 29^{+}$; $\mathrm{CD} 24^{+}$in at least some mouse mammary cancers [15]) or by aldehyde dehydrogenase activity [16]. While transplantation is the gold standard for demonstrating both normal and malignant stem cell behaviors, it is important to recognize that dissociated cells may not always behave as would intact tissue fragments, and that transplantation success depends not only on the ability of cells to divide, but also on their ability to recruit a new blood supply and interact appropriately with the environment in which they are placed. Thus, these limitations may lead us to underestimate the true number and regenerative capacity of both normal and malignant mammary stem cells.

For argument's sake, let's assume that breast cancer stem cells exist. Before one can understand the origin and properties of breast cancer stem cells, it is critical to elucidate the various cell lineages in the normal mammary gland. Thus, our profound ignorance of the identity, behavior, regulation and differentiation of stem and progenitor cells in the normal mammary gland is a significant barrier to progress. Furthermore, until we achieve a higher level appreciation for the biology of the normal breast, development of safe, effective breast cancer prevention and treatment strategies will likely remain an elusive goal. These sentiments were formalized a decade ago in a National Cancer Institute Program Review Group Summary Report [17]. Their words ring as true today as they did then.

"...it is essential that questions
concerning the cell of origin, relative
frequency, quiescence, regulation,
therapy resistance and metastatic
behavior of cancer stem cells be
addressed wholly independently of the
question of their existence."

The three questions intimated above serve to illustrate this point. First, assuming breast cancer stem cells exist, 'what are the cells of origin?' Second, 'are breast cancer stem cells intrinsically resistant to current therapies, and if so, by what mechanisms?' Finally, 'if breast cancer stem cells are inherently resistant to current therapies, how can we eliminate them?'

"..the term 'stem cell' in the 'cancer
stem cell hypothesis' refers to a defining
set of cellular behaviors responsible for
tumor formation, and not necessarily to
the identity of the cell of origin."

With respect to the cell(s) of origin, in the mouse mammary gland, several normal cell types already possess some level of self-renewal capacity, including both regenerative stem cells [18-20] and progenitor cells (e.g., myoepithelial, ductal and alveolar progenitor cells) [21-23]. Thus, these cell types are the obvious best candidates for the cells of origin of breast cancer [2]. However, there are currently no data to exclude the possibility that 'differentiated' cells lacking an overt self-renewal and differentiation capacity cannot acquire the ability to self-renew and differentiate under the right genetic or epigenetic circumstances [24-26]. The recent breakthroughs in genetic 'reprogramming' of differentiated somatic cells into pluripotent cells with stem cell properties suggest that self-renewal and re-acquisition of multilineage differentiation capacity in cell types once considered terminally differentiated is possible [26-30]. In fact, one of the genes involved in this reprogramming, $c-M y c$, is frequently overexpressed in breast cancer and has been shown to activate an embryonic stem cell-like transcriptional program in differentiated adult cells, resulting in the pathologic self-renewal characteristic of cancer stem cells [31].

Is there any evidence that something such as 'reprogramming' or 'respecification' might occur in the normal mammary gland? In fact, there just may be. Elegant genetic tagging experiments in mice suggest that a subset of 'differentiated' alveolar epithelial cells survive the involution process after weaning and retain a high degree of regenerative and multilineage differentiation capacity upon transplantation. Furthermore, these cells can participate in oncogene-induced tumor formation $[32,33]$. Even more stunning is an intriguing set of results suggesting that mammary epithelial cells are capable of respecifying the identity and fate of non-mammary cells derived from seminiferous tubules, as well as neural stem cells, such that they participate in mammary gland regeneration upon transplantation and are capable of secretory differentiation during lactation $[34,35]$. While these results have 
yet to be explained fully, it is clear that we still have a great deal to learn about the relationship between differentiation and forfeiture of selfrenewal, regarding the role epithelial-epithelial and epithelial-stromal interactions play in specifying mammary epithelial cell identity and fate, and regarding the degree of developmental plasticity 'differentiated' mammary epithelial cells may retain.

Are breast cancer stem cells intrinsically resistant to current therapies? The suggestion was made recently that we may be going about breast cancer treatment incorrectly by targeting the rapidly dividing cells in the tumor using conventional systemic therapies, and leaving treatment-refractory cancer stem cells behind [36]. This hypothesis was dubbed the 'dandelion hypothesis' by analogy to the propensity of these weeds to regenerate from the root after the leaves have been plucked. Indeed, there is mounting evidence that normal mammary stem cells and breast cancer cells with tumor-initiating capacity are, by their nature, more resistant to radiation and chemotherapeutic agents than are their progeny, such that tumor-initiating cells actually make up a larger proportion of cells in residual tumors after chemotherapy [37-40]. If confirmed, these data provide a plausible explanation as to why conventional systemic therapies are effective in controlling tumor growth initially, but fail to prevent recurrence in nearly all patients with metastatic disease, and approximately a quarter of those with early disease, despite apparent clinical response to treatment [41]. Such data would also indicate that the current criteria for evaluating clinical efficacy of therapeutic agents (tumor shrinkage) may be completely inadequate, as they do not evaluate the cancer stem cell response. Importantly, this intrinsic form of resistance (perhaps by more efficient drug efflux, cell-cycle checkpoint control and DNA repair) should not preclude the possibility of other acquired resistance mechanisms (e.g., mutation or growth factor activation) arising over time.

\footnotetext{
"... until we achieve a higher level appreciation for the biology of the normal breast, development of safe, effective breast cancer prevention and treatment strategies will likely remain an elusive goal."
}

Finally, if the breast cancer stem cell is refractory to current treatments, how can they be eliminated? The mechanism(s) of intrinsic therapy resistance in normal and malignant mammary stem cells are largely unknown. Current efforts to target breast cancer stem cells are focused primarily on the two defining features of cancer stem cells, self-renewal and differentiation capacity. For 'self-renewal therapy', we and others are investigating inhibitors of signaling networks implicated in the control of normal and malignant stem cell self-renewal or maintenance (e.g., Hedgehog, Notch, Wnt and ErbB2 signaling) [38,41]. Indeed, our clinical studies indicate that, at least in HER $2^{+}$tumors, tumor-initiating cells can be targeted for more efficient elimination by the dual tyrosine kinase inhibitor lapatinib in the neoadjuvant setting, in conjunction with chemotherapy/trastuzumab [40]. In addition, several laboratories are exploring 'differentiation therapy', which entails treatment with agents that tend to force stem/progenitor cells to differentiate, thereby potentially decreasing self-renewal capacity and rendering them either inconsequential to the patient, or sensitive to systemic therapies $[2,38,42]$.

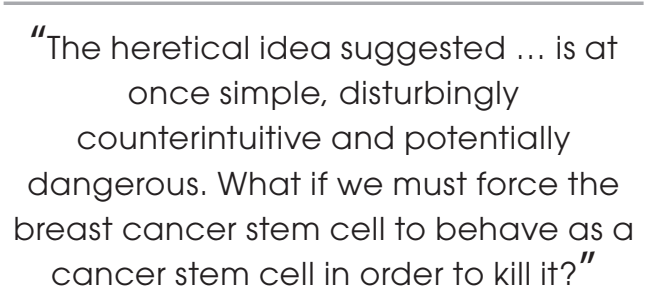

While these new approaches are extremely exciting and potentially revolutionary, in our rush to test self-renewal inhibitors and prodifferentiation agents, are we at risk of going about this all wrong once again? For example, if one simply prevents self-renewal without killing the cancer stem cell, what is to prevent the tumor from recurring once therapy is stopped? Even if one kills or differentiates all the cancer stem cells present at a given time, what influence might developmental plasticity of remaining epithelium have on tumor relapse and clinical outcome?

In the normal mouse mammary gland, regenerative stem cells are distributed throughout the ductal tree. However, transplantation experiments suggest that regenerative stem cells in the mature duct are not generally actively engaged in stem cell behaviors and are strongly growthinhibited by the presence of neighboring normal mammary epithelium. The nagging question then arises: what if some cancer stem cells behave similarly? If a cancer stem cell in a tumor is not actively engaged in cancer stem 
cell behaviors, will they not be refractory to selfrenewal inhibitors and differentiation agents? Sadly, the answer is likely to be yes.

The heretical idea suggested by these possibilities is at once simple, disturbingly counterintuitive and potentially dangerous. What if we must force the breast cancer stem cell to behave as a cancer stem cell in order to kill it? What if we must drive activation of the cancer stem cells and force self-renewal? Alternatively, what if we need to prevent the cancer stem cell from differentiating, or from becoming quiescent? Unfortunately, we currently have little idea how to accomplish any of these tasks. As a result, these alternative hypotheses cannot currently be tested adequately.

Given our current level of ignorance, the risk with any of the treatment approaches described previously is the high potential for failure, or even for making a bad situation worse. In the midst of all this uncertainty, three things are clear. First, if we are to have faith in the promise of individualized medicine for breast cancer treatment, we must define the cell(s) of origin for breast cancer and understand their differential regulation. Second, in order to prevent or cure the broadest range of cancers possible, we must develop improved, relevant, preclinical models in which to explore the varied competing hypotheses related to the targeting of tumor-initiating cells. Finally, we must discard any unsubstantiated, preconceived notions regarding the nature of cancer stem cells. To this end, a little heresy now and then might be very useful.

\section{Financial \& competing interests disclosure \\ The author is supported by National Institute of Health grants RO1-CA127857, P01-CA30195 and P50-CA58183, as well as by research grants from Cancer Fighters of Houston and Infinity Pharmaceuticals. The author has no other relevant affiliations or financial involvement with any organization or entity with a financial interest in or financial conflict with the subject matter or materials discussed in the manuscript apart from those disclosed. \\ No writing assistance was utilized in the production of this manuscript.}

\section{Bibliography}

1. DeOme KB, Faulkin LJJ, Bern H: Development of mammary tumors from hyperplastic alveolar nodules transplanted into gland-free mammary fat pads of female C3H mice. Cancer Res. 19, 515-520 (1958).

2. Sell S: Stem cell origin of cancer and differentiation therapy. Crit. Rev. Oncol. Hematol. 51, 1-28 (2004).

3. Wicha MS: Breast cancer stem cells: the other side of the story. Stem Cell Rev. 3, 110-112; discussion 3 (2007).

4. Polyak K: Breast cancer stem cells: a case of mistaken identity? Stem Cell Rev. 3, 107-109 (2007).

5. Shipitsin M, Polyak K: The cancer stem cell hypothesis: in search of definitions, markers, and relevance. Lab. Invest. 88, 459-463 (2008)

6. Hill RP: Identifying cancer stem cells in solid tumors: case not proven. Cancer Res. 66, 1891-1895; discussion 0 (2006).

7. McBride SM: Natural selection's challenge to the cancer stem cell hypothesis. Med. Hypotheses 71(3), 471-472 (2008).

8. Lobo NA, Shimono Y, Qian D, Clarke MF: The biology of cancer stem cells. Annu. Rev. Cell Dev. Biol. 23, 675-699 (2007).

9. Kern SE, Shibata D: The fuzzy math of solid tumor stem cells: a perspective. Cancer Res. 67, 8985-8988 (2007).
10. Kolata G: Scientists weigh stem cells' role as cancer cause. The New York Times, 21 December (2007).

11. Kelly PN, Dakic A, Adams JM, Nutt SL, Strasser A: Tumor growth need not be driven by rare cancer stem cells. Science 317, 337 (2007).

12. Kennedy JA, Barabe F, Poeppl AG, Wang JC, Dick JE: Comment on "tumor growth need not be driven by rare cancer stem cells". Science 318, 1722 (2007).

13. Adams JM, Strasser A: Is tumor growth sustained by rare cancer stem cells or dominant clones? Cancer Res. 68, 4018-4021 (2008).

14. Al-Hajj M, Wicha MS, Benito-Hernandez A, Morrison SJ, Clarke MF: Prospective identification of tumorigenic breast cancer cells. Proc. Natl Acad. Sci. USA 100, 3983-3988 (2003).

15. Zhang M, Behbod F, Atkinson RL $e$ tal.: Identification of tumor-initiating cells in a p53-null mouse model of breast cancer. Cancer Res. 68, 4674-4682 (2008).

16. Ginestier C, Hur MH, Charafe-Jauffret $\mathrm{E}$ et al: ALDH1 is a marker of normal and malignant human mammary stem cells and a predictor of poor clinical outcome. Cell Stem Cell 1, 555-567 (2007).

17. Moses H, Davidson N: Charting the Course: Priorities for Breast Cancer Research. National Cancer Institute Program Review Group Summary Report (1998).
18. Moraes RC, Zhang X, Harrington N et al:: Constitutive activation of smoothened (SMO) in mammary glands of transgenic mice leads to increased proliferation, altered differentiation and ductal dysplasia. Development 134, 1231-1242 (2007).

19. Stingl J, Eirew P, Ricketson I et al.: Purification and unique properties of mammary epithelial stem cells. Nature 439, 993-997 (2006).

20. Shackleton M, Vaillant F, Simpson KJ et al.: Generation of a functional mammary gland from a single stem cell. Nature 439, 84-88 (2006).

21. Smith GH: Experimental mammary epithelial morphogenesis in an in vivo model: evidence for distinct cellular progenitors of the ductal and lobular phenotype. Breast Cancer Res. Treat. 39, 21-31 (1996).

22. Daniel CW, Young LJ, Medina D, DeOme KB: The influence of mammogenic hormones on serially transplanted mouse mammary gland. Exp. Gerontol. 6, 95-101 (1971).

23. Williams JM, Daniel CW: Mammary ductal elongation: differentiation of myoepithelium and basal lamina during branching morphogenesis. Dev. Biol. 97, 274-290 (1983).

24. Rapp UR, Ceteci F, Schreck R: Oncogene-induced plasticity and cancer stem cells. Cell Cycle 7, 45-51 (2008).

25. Mani SA, Guo W, Liao MJ et al.: The epithelial-mesenchymal transition generates cells with properties of stem cells. Cell 133, 704-715 (2008). 
26. Akala OO, Park IK, Qian D, Pihalja M, Becker MW, Clarke MF: Long-term haematopoietic reconstitution by $\operatorname{Tr} 53^{-1-}$ p16Ink $4 \mathrm{a}^{-/}$p19Arf ${ }^{-}$multipotent progenitors. Nature 453, 228-232 (2008).

27. Park IH, Zhao R, West JA et al. Reprogramming of human somatic cells to pluripotency with defined factors. Nature 451, 141-146 (2008)

28. Takahashi K, Tanabe K, Ohnuki M et al.: Induction of pluripotent stem cells from adult human fibroblasts by defined factors. Cell 131, 861-872 (2007).

29. Wernig M, Lengner CJ, Hanna J et al.: A drug-inducible transgenic system for direct reprogramming of multiple somatic cell types. Nat. Biotechnol. 26(8), 916-924 (2008).

30. Kim JB, Zaehres H, Wu G et al.: Pluripotent stem cells induced from adult neural stem cells by reprogramming with two factors. Nature 454(7204), 646-650 (2008).

31. Wong DJ, Liu H, Ridky TW, Cassarino D, Segal E, Chang HY: Module map of stem cell genes guides creation of epithelial cancer stem cells. Cell Stem Cell 2, 333-344 (2008).

32. Boulanger CA, Wagner KU, Smith GH: Parity-induced mouse mammary epithelial cells are pluripotent, self-renewing and sensitive to TGF- $\beta 1$ expression. Oncogene 24, 552-560 (2005).
33. Matulka LA, Triplett AA, Wagner KU: Parity-induced mammary epithelial cells are multipotent and express cell surface markers associated with stem cells. Dev. Biol. 303, 29-44 (2007).

34. Boulanger CA, Mack DL, Booth BW, Smith GH: Interaction with the mammary microenvironment redirects spermatogenic cell fate in vivo. Proc. Natl Acad. Sci. USA 104, 3871-3876 (2007).

35. Booth BW, Mack DL,

Androutsellis-Theotokis A, McKay RDG, Boulanger CA, Smith GH: The mammary microenvironment alters the differentiation repertiore of neural stem cells. Proc. Natl Acad. Sci. USA (2008) (In press).

36. Jones RJ, Matsui WH, Smith BD: Cancer stem cells: are we missing the target? J. Natl. Cancer Inst. 96, 583-585 (2004).

37. Eyler CE, Rich JN: Survival of the fittest: cancer stem cells in therapeutic resistance and angiogenesis. J. Clin. Oncol. 26, 2839-2845 (2008).

38. Kakarala M, Wicha MS: Implications of the cancer stem-cell hypothesis for breast cancer prevention and therapy. J. Clin. Oncol. 26, 2813-2820 (2008).
39. Woodward WA, Chen MS, Behbod F, Alfaro MP, Buchholz TA, Rosen JM: $\mathrm{WNT} / \beta$-catenin mediates radiation resistance of mouse mammary progenitor cells. Proc. Natl Acad. Sci. USA 104, 618-623 (2007).

40. Li X, Lewis MT, Huang J et al.: Intrinsic resistance of tumorigenic breast cancer cells to chemotherapy. J. Natl. Cancer Inst. 100, 672-679 (2008).

41. EBCTG: Polychemotherapy for early breast cancer: an overview of the randomised trials. Lancet 352, 930-942 (1998).

42. Charafe-Jauffret E, Monville F, Ginestier C, Dontu G, Birnbaum D, Wicha MS: Cancer stem cells in breast: current opinion and future challenges. Pathobiology 75, 75-84 (2008).

\section{Affiliation}

- Michael T Lewis

Lester and Sue Smith Breast Center and the Department of Molecular and Cellular Biology, Baylor College of Medicine, One Baylor Plaza, Room N1210, BCM600, Houston TX 77030, USA

Tel.: +1 7137983296

Fax: +17137981659

mtlewis@bcm.tmc.edu 